\title{
Partial oxidation of methane to methanol over catalyst ZSM-5 from coal fly ash and rice husk ash
}

\author{
Fusia Mirda Yanti ${ }^{1, *}$, S.D. Sumbogo Murti ${ }^{1}$, and Yuni K. Krisnandi ${ }^{2}$, Adiarso ${ }^{1}$ \\ ${ }^{1}$ Agency for Assessment and Application of Technology, 10340 Jakarta, Indonesia \\ ${ }^{2}$ Department of Chemistry Faculty of Mathematics and Natural Science Universitas Indonesia, 16424 Depok, Indonesia
}

\begin{abstract}
Methane is one of the greenhouse gases that can be converted into liquid fuels such as methanol to retain most of the energy of methane and produce a cleaner environment. The conversion of methane to methanol using ZMS-5 represents a breakthrough in the utilization of methane. However, material sources for zeolite synthesis as catalyst usually are pro-analysis grade materials, which are expensive. Therefore, in this research, coal fly ash and rice husk ash were used as raw materials for mesoporous ZSM-5 zeolite synthesis. First, coal fly ash and rice husk were subjected to pre-treatment to extract silicate $\left(\mathrm{SiO}_{4}{ }^{4-}\right)$ and aluminate $\left(\mathrm{AlO}_{4}{ }^{5-}\right)$ and impurities separation. The ZSM-5 zeolite was synthesized through hydrothermal treatment using two types of templates. After ZSM-5 was synthesized, it was modified with Cobalt through impregnation method. The catalytic activity of both ZSM-5 and Co/ZSM-5 zeolites as heterogeneous catalysts in partial oxidation of methane were preliminary tested and compared with that commercial one. The result showed that the zeolite catalyst ZSM-5 from fly ash coal and rice husk ash has the potential to be used as catalysts in the partial oxidation of methane to methanol.
\end{abstract}

\section{Introduction}

Methane $\left(\mathrm{CH}_{4}\right)$ and carbon dioxide $\left(\mathrm{CO}_{2}\right)$ are major components of biogas which are generated in landfills as the result of waste decomposition and in the treatment of wastewater [1]. Methane, the most plentiful component of natural gas, is a useful material for synthesis of more valuable product such as ethylene, methanol or formaldehyde. Methane is also a part of greenhouse gases, so it is desirable to convert methane into liquid transportable fuels such as methanol because it retains most of methane energy and produce clean environment [2]. Recently, in order to utilize methane, partial oxidation reaction becomes one of main research interests. Partial oxidation is a technically mature process in which gas or a heavy hydrocarbon fuel (heating oil) is mixed with a limited amount of oxygen in an exothermic process. Research in methane conversion to methanol and formaldehyde through partial oxidation using ZSM-5 zeolite as heterogeneous catalyst at $423 \mathrm{~K}$ has been reported [3].

Methanol is one bulk chemical being widely used in chemical industry. Methanol is used as solvent, a gasoline additive and a chemical feedstock for production of biodiesel and hundreds of other chemical [4]. Besides that, methanol also is widely regarded as promising alternative for automobile fuel. Introduction of automobiles and other transportation vehicles that are able to bum pure or blended methanol would be highly benefical as per enviromental energy considerations [5].
Some of positives effects of developing a world-wide market for methanol as a fuel are: (a) decrease in dependency on foreign energy sources, (b) conservation of existing petroleum based energy reserves, (c) increased competition among energy providers resulting in lower cost and (d) enviromental benefits from improved emissions inherent in the combustion of methanol as compared to petroleum-base fuels. Adoption of methanol as a primary automobile or transportation fuel would necessitate a large increase in the world's methanol production capacity. This would make methane a much more attractive and valuable energy sources which is easily transportable as compared to its origin [6].

Beznis et al... [7] has been investigated the oxidation of methane to methanol and formaldehyde over Co-ZSM-5 molecular sieves. Eugeny et al. [8] also has been investigated about oxidation methane to methanol on the surface of FeZSM-5 zeolite. Krisnandi et al. [1] also has been researched partial oxidation of methane over heterogeneous catalyst Co/ZSM-5 with two type structures: microporous and hierarchical. The result showed that the hierarchical Co/ZSM-5 catalyst give the highest conversion of methane to methanol. However, material sources for zeolite synthesis as catalyst usually are pro-analysis grade materials, which are expensive. Therefore, in this research, coal fly ash and rice husk ash were used as raw materials for mesoporous ZSM-5 zeolite synthesis.

* Corresponding author: fusia.mirda@bppt.go.id 


\section{Experimental}

\subsection{Materials}

The materials used were: Coal Fly Ash from Paiton, Indonesia, rice husk from Bogor, Indonesia, sodium hydroxide $(\mathrm{NaOH})$ pellet, Chloride acid $(\mathrm{HCl}) 1 \mathrm{M}$, Tetrapropylammonium hydroxide, TPAOH 1M (Sigma Aldrich), Poly Diallyl Dimethyl Ammonium Chloride (PDDA $35 \%$ ) (Aldrich), Cobalt (II) Nitrate $\left(\mathrm{Co}\left(\mathrm{NO}_{3}\right)_{2} .6 \mathrm{H}_{2} \mathrm{O}\right)$ (Sigma Aldrich), methane gas (99.99 $\%$ BOC), $\mathrm{N}_{2}$ gas (99.99\% UHP) and deionized water.

\subsection{Pretreatment of Coal Fly Ash}

Coal fly ash was dried and sieved using a 200 mesh sieve, and then activated in a furnace at a temperature of $800{ }^{\circ} \mathrm{C}$ for 2 hours, followed by refluxing with $1 \mathrm{M} \mathrm{HCl}$ for 3 hours at $90{ }^{\circ} \mathrm{C}$. After this, the mixture was washed with distilled water to $\mathrm{pH}$ neutral. The products were filtered with filter paper and then dried in an oven with a temperature of $105{ }^{\circ} \mathrm{C}$ for 6 hours. Characterization of product was carried out by AAS, FTIR, and XRD

\subsection{Pretreatment of Rice Husk Ash}

Risk husk samples (500 grams) was washed and then dried in an oven at $105{ }^{\circ} \mathrm{C}$ for 1 hour. After that, the sample was crushed and sieved into 60 meshes, then burned with a furnace at $700{ }^{\circ} \mathrm{C}$ for 4 hours. Sample was characterized by AAS, FTIR and XRD

\subsection{Synthesis of ZSM-5 Catalyst}

Synthesis of ZSM-5 catalyst was prepared with a molar ratio: $12 \mathrm{NaOH}: 30 \mathrm{SiO}_{2}$ : $0.75 \mathrm{Al}_{2} \mathrm{O}_{3}$ : 6 TPAOH: 1800 $\mathrm{H}_{2} \mathrm{O}$ [9]. In this experiment, $2.0286 \mathrm{~g}$ of coal fly ash was mixed with $30 \mathrm{ml}$ of $0.4 \mathrm{M} \mathrm{NaOH}$ solution (mixture A) at $100{ }^{\circ} \mathrm{C}$. Then $5.7187 \mathrm{~g}$ rice husk ash was added with $70 \mathrm{ml}$ of $0.4 \mathrm{M} \mathrm{NaOH}$ and then stirred at $100{ }^{\circ} \mathrm{C}$ (mixture B). Furthermore, mixture's B was slowly added to the mixture A, then $4.0552 \mathrm{~g} \mathrm{TPAOH}$ was added to the mixture, and glacial acetic acid was added to adjust $\mathrm{pH}$ up to 11. Stirring was continued for 3 hours at a temperature of $100{ }^{\circ} \mathrm{C}$. After that, added $1 \mathrm{~g}$ of PDDA $(10 \mathrm{wt} \%)$ to the mixture and stirred again for 15 hours at room temperature. Then the reaction mixture was transferred into the autoclave and heated for 144 hours at a temperature of $150{ }^{\circ} \mathrm{C}$ in the oven. The reaction product was be cooled, washed with aquademin, filtered, and dried at room temperature for one night. After that, the product was calcined for 8 hours at a temperature of $500{ }^{\circ} \mathrm{C}$. The synthesized crystals of mesoporous ZSM-5 was characterized by XRD instruments, FTIR, SEM, and pore size analyzer (BET).
Post-synthesis modification was carried out to obtain Co/ZSM5 by following the procedure as reported previously [1], i.e. by mixing $0.2495 \mathrm{M}$ cobalt solution (from $\mathrm{Co}\left(\mathrm{NO}_{3}\right)_{2}$ ) with the zeolite. After the impregnation process, the mixture was calcined at $500{ }^{\circ} \mathrm{C}$ to obtain Co/ZSM-5

\subsection{Application for Partial Oxidation of Methane to Methanol}

Testing of catalytic partial oxidation of methane to methanol in a stainless steel vessel as a batch reactor was carried out. The testing procedure has been reported previously [1]. The catalyst used for each reaction is 0.5 $\mathrm{g}$, which has been activated at $500{ }^{\circ} \mathrm{C}$. The reaction was performed at $150{ }^{\circ} \mathrm{C}$ with methane pressure of 0.75 bar and a nitrogen pressure of 2 bar with a variety of reaction time of 30 minutes and 60 minutes then extracted with ethanol, and characterized using Gas Chromatography-FID.

\section{Results and Discussion}

\subsection{Synthesis of ZSM-5 catalyst}

The mesoporous ZSM-5 zeolite from fly ash and rice husk ash were synthesized through hydrothermal treatment using two types of templates (TPAOH and PDDA). First, coal fly ash and rice husk were subjected to pre-treatment in order to extract silicate $\left(\mathrm{SiO}_{4}{ }^{4-}\right)$ and aluminate $\left(\mathrm{AlO}_{4}{ }^{5-}\right)$ and separated from the impurities. The ZSM-5 zeolites were synthesized using TPAOH as the micropore template and structure-directing agent for MFI-type zeolite, whereas in order to create mesoporosity within the structure, PDDA polycation was added. Soft templates such as PDDA have two possible positions in the zeolite, during the crystallization process, in which it could coat on the inside and outside of the zeolite particles

Figure 1 showed diffraction pattern of coal fly ash, rice husk, and catalyst ZSM-5. Figure 1 showed the appearance of certain peak of rice husk in the position 2 theta at $21^{0}$, indicative of amorphous silica, and the coal fly ash contained silica quartz peaks with low intensity at position 2 theta $26.5^{\circ}$. In addition there is a silica quartz, the coal fly ash also contained the peak of hematite $\left(\mathrm{Fe}_{2} \mathrm{O}_{3}\right)$ at position 2 theta $24^{0} ; 33^{0} .49^{0} ; 54^{0}, 62^{0}$ and magnetite $\left(\mathrm{Fe}_{3} \mathrm{O}_{4}\right)$ at position 2 theta $31^{0 ;} 36^{0} ; 43^{0} ; 57^{0}$; $63^{\circ}[10]$. Diffraction patterns of ZM-5 from fly ash dan rice husk ash showed the appearance of certain peaks in the position 2 theta between $7^{\circ}$ to $9^{\circ}$ and $22^{\circ}$ to $25^{\circ}$ (Figure 1), indicative of successfully synthesized ZSM-5 structure [11]. 


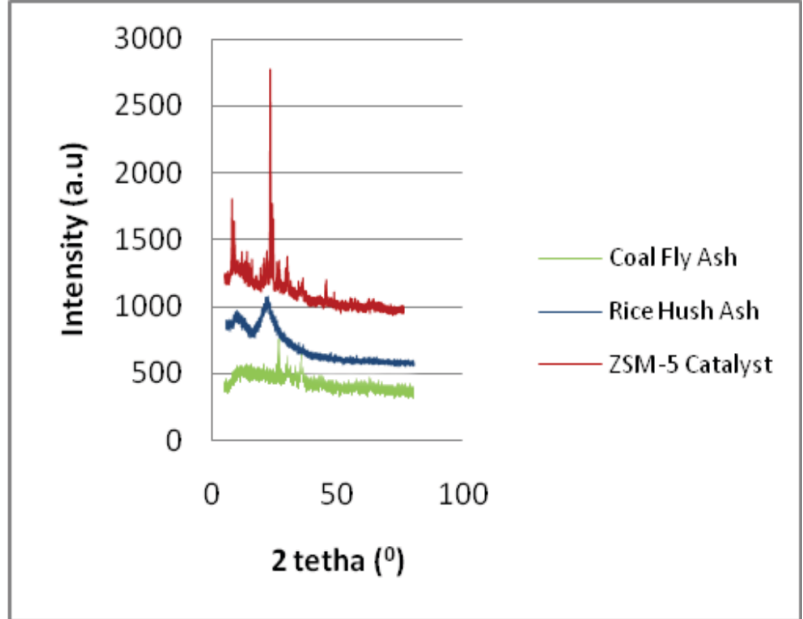

Fig 1. XRD Pattern of Coal Fly Ash, Rice Husk Ash and ZSM5 Catalyst

Figure 2 shows the FTIR spectra of ZSM-5. The characteristic absorption bands of ZSM-5 were found at around 1250-950 cm $\mathrm{cm}^{-1}\left(v_{\text {asimetri }}\right.$ T-O), $1100-700 \mathrm{~cm}^{-1}$ $\left(v_{\text {simetri }} \mathrm{T}-\mathrm{O}\right)$, and also were found at round $650-500 \mathrm{~cm}^{-1}$ indicated the presence of double 5- ring in ZSM-5.[12].

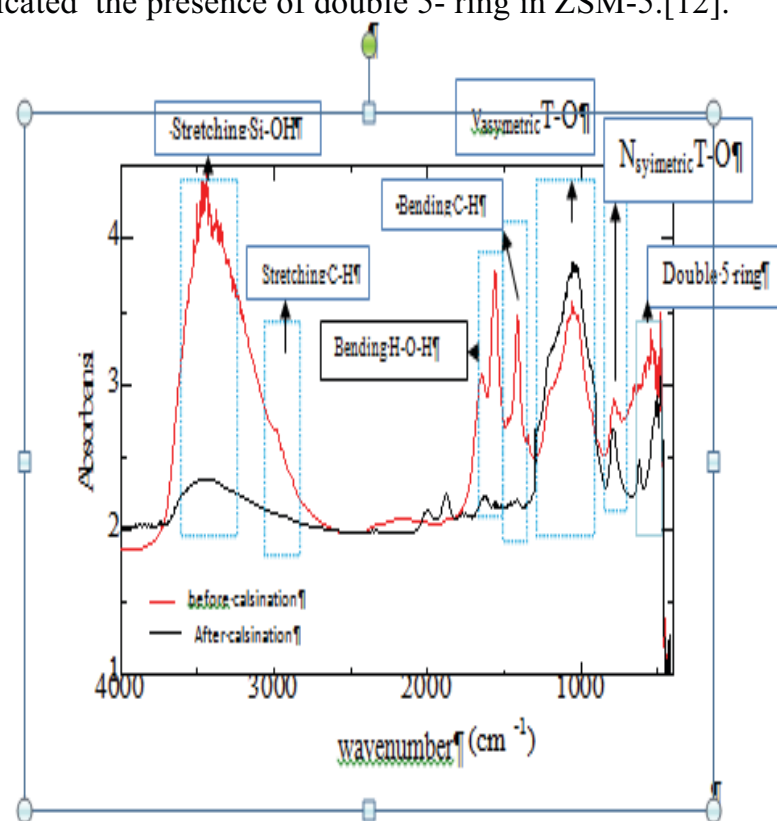

Fig 2. Spectra FTIR of ZSM- 5 zeolite catalyst

Table 1 shows the chemical content of fly ash, rice husk ash, ZSM-5 zeolite and the $\mathrm{Si} / \mathrm{Al}$ ratio of synthesized ZSM-5. Rice husk ash contains the main components such as silica, so it is potentially used as a source of silica for synthesis of ZSM-5 catalyst. Coal fly ash main content are $\mathrm{SiO}_{2}, \mathrm{Al}_{2} \mathrm{O}_{3}, \mathrm{Fe}_{2} \mathrm{O}_{3}$, and $\mathrm{CaO}$. Ratio of $\mathrm{Si} / \mathrm{Al}$ ratio to ZSM-5 from fly ash is 16.73 . Catalyst ZSM-5 synthesized from fly ash coal and rice husk ash has other components beside $\mathrm{Si}$ and $\mathrm{Al}$ like $\mathrm{Fe}, \mathrm{Ca}, \mathrm{Mg}$ and $\mathrm{Mn}$.
Table 1. Chemical content (\%wt) of rice husk ash, fly ash,and ZSM-5 catalyst.

\begin{tabular}{|c|c|c|c|}
\hline Component & $\begin{array}{c}\text { Rice husk } \\
\text { ash }\end{array}$ & Fly ash & $\begin{array}{c}\text { ZSM-5 } \\
\text { Catalyst }\end{array}$ \\
\hline $\mathrm{SiO}_{2}$ & 93.73 & 30.19 & 66.34 \\
\hline $\mathrm{Al}_{2} \mathrm{O}_{3}$ & 0.63 & 14.28 & 2.91 \\
\hline $\mathrm{Fe}_{2} \mathrm{O}_{3}$ & 0.00 & 20.20 & 5.67 \\
\hline $\mathrm{CaO}$ & 0.00 & 19.93 & 12.79 \\
\hline $\mathrm{MgO}$ & 0.26 & & 2.74 \\
\hline $\mathrm{Na}_{2} \mathrm{O}$ & 0.16 & 1.65 & 1.25 \\
\hline $\mathrm{K}_{2} \mathrm{O}$ & 2.14 & 1.19 & 1.36 \\
\hline $\mathrm{TiO}_{2}$ & - & 0.79 & - \\
\hline $\mathrm{PO}_{5}$ & - & 0.42 & - \\
\hline $\mathrm{Mn}_{3} \mathrm{O}_{4}$ & 0.11 & 0.22 & 0.12 \\
\hline $\mathrm{SO}_{3}$ & - & 1.58 & - \\
\hline & & & \\
\hline
\end{tabular}

The morphology of crystals ZSM-5 is hexagonal form with unsmooth or rough surface indicating the formation of mesoporous feature on the surface of the crystal (Figure.3).

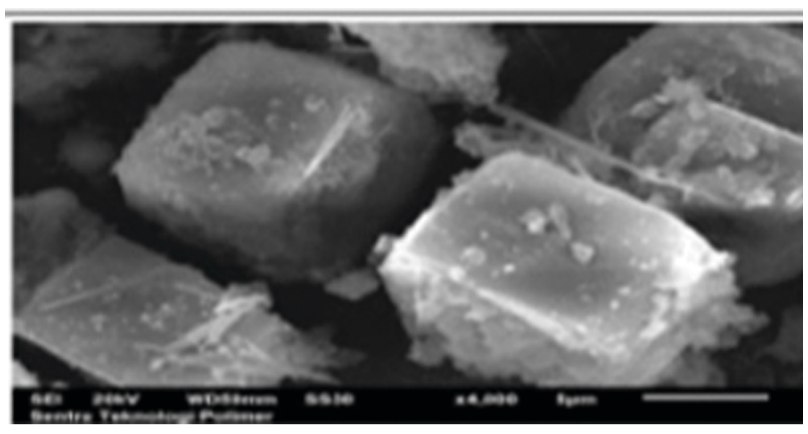

Fig.3 . SEM image of ZSM-5 zeolite

The results of surface area analyses of ZSM-5 are summarized in Table 2.

Table 2. Surface area analyses of ZSM-5 calculated from BET

\begin{tabular}{|c|c|c|c|c|c|c|}
\hline Sample & $\begin{array}{c}\text { S BET } \\
(\mathrm{m} 2 / \mathrm{g})\end{array}$ & $\begin{array}{c}\text { S ext } \\
(\mathrm{m} 2 / \mathrm{g})\end{array}$ & $\begin{array}{c}\text { V tot } \\
(\mathrm{cm} / \mathrm{g})\end{array}$ & $\begin{array}{c}\text { V meso } \\
(\mathrm{cm} 3 / \mathrm{g})\end{array}$ & $\begin{array}{c}\text { Average } \\
\text { V micro } \\
(\mathrm{cm} 3 / \mathrm{g})\end{array}$ & $\begin{array}{c}\text { diameter } \\
\text { pore } \\
(\mathrm{nm})\end{array}$ \\
\hline ZSM-5 & 43.759 & 43.759 & 0.287 & 0.287 & - & 26.2618 \\
\hline
\end{tabular}

Table 2 shows that the surface area of ZSM-5 catalyst from fly ash and rice husk ash is low, due to ZSM-5 from fly ash and rice husk ash still has many impurities especially $\mathrm{Fe}$ which could as inhibitor in zeolititation process. From Table 2 also shows the pore diameter of ZSM-5 catalyst of $26.26 \mathrm{~nm}$, indicating formed mesoporous (IUPAC: mesoporous 2-50 nm). The adsorption isotherm curve for ZSM-5 is shown in Figure 4. 


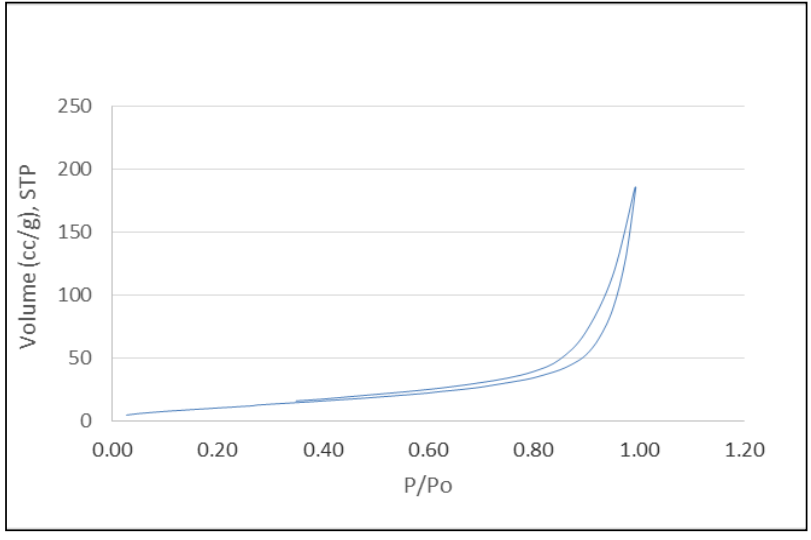

Fig 4. Isotherm adsorption-desorption plots of ZSM-5 catalyst

\subsection{Catalytic test: partial oxidation of methane to methanol}

Catalytic partial oxidation of methane to methanol was conducted in a vessel of stainless steel as a batch reactor by following the procedure have been reported previously [1]. Prior to the catalytic reaction, the ZSM-5 catalyst must be first activated at a temperature of $500{ }^{\circ} \mathrm{C}$ with the aim to form cobalt oxide species which constitute the active site of the catalyst Co/ZSM-5. Furthermore, flushing was carried out using nitrogen gas to remove organic impurities, water vapour and excess oxygen in the reactor. The condition of the reaction was adapted from the work reported by Krisnandi et al.. [1] and Bezniz et.al [7]. The first set of experiments was carried out at $150{ }^{\circ} \mathrm{C}$ with reaction time of 30 minutes and 60 minutes, and $\mathrm{CH}_{4}$ pressure (Pmethane) of 0.75 Bar in $200 \mathrm{~cm}^{3}$ stainless steel vessel.

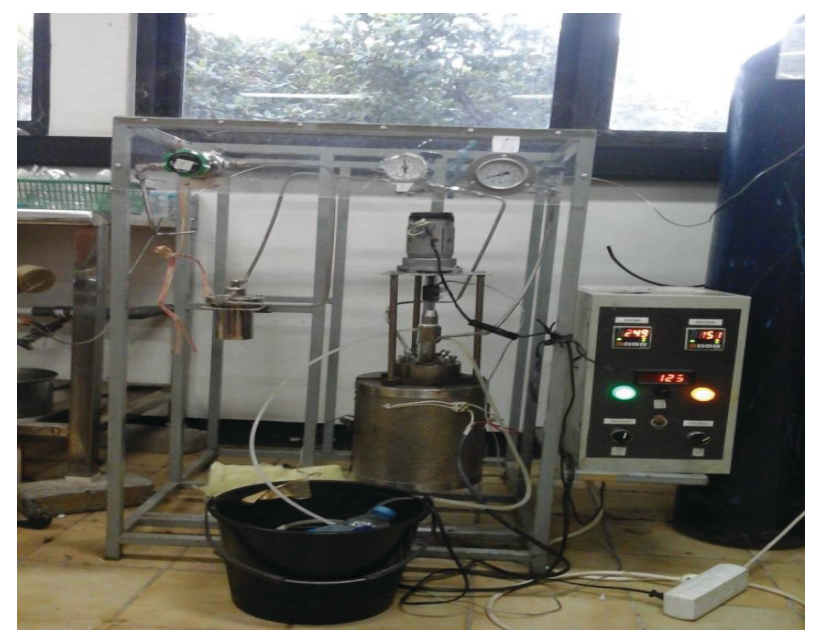

Fig 5. Batch reactor for partial oxidation of methane to methanol

The results of this experiment are summarized in Figure 6

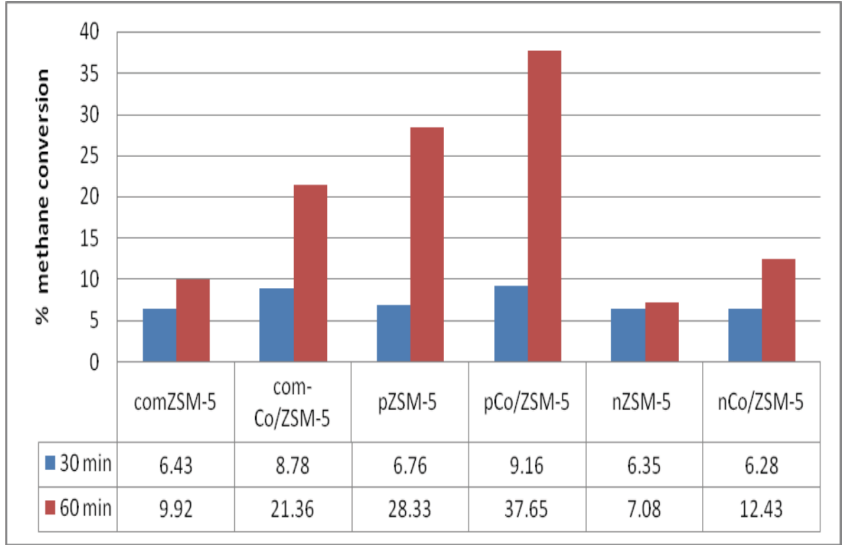

Fig 6. Percentage of methane conversion to methanol in reaction carried out at $150{ }^{\circ} \mathrm{C}, \mathrm{t}=30$ and $60 \mathrm{~min}$ and methane partial pressure of $0.75 \mathrm{Bar}$

Figure 6 showed that the catalytic activity of ZSM5 and Co/ZSM-5 from fly ash and rice husk was still inferior ( $7.08 \%$ and $12.43 \%$ conversion of methane) compared to the pro-analysis materials $(28.33 \%$ and $37.65 \%)$ and commercial one $(9.92 \%$ and $21.36 \%)$. However, they were potential to be used as catalyst in the partial oxidation of methane to methanol. The activity of ZSM-5 and Co/ZSM-5 from fly ash and rice husk ash inferior compared to the pro-analysis materials because ZSM-5 from fly ash and rice husk has lower surface area than ZSM-5 pro-analysis materials. The cobalt-loaded ZSM-5 catalysts gave higher conversion than the ZSM-5 without cobalt-loaded because impregnated Co/ZSM-5, mainly containing cobalt oxide species at the zeolite outer surface, were more selective towards methanol [7]

The mechanisms (modified from[13]) that occurred during the partial oxidation of methane to methanol are as follows:

Step 1, C-H activation

$\mathrm{OM}-\mathrm{ZSM}-5+\mathrm{CH}_{4}-(\cdot \mathrm{HO})-\mathrm{M}-\mathrm{ZSM}-5+\cdot \mathrm{CH}_{3}$

Step 2, formation of hidroxy

$(\cdot \mathrm{HO})-\mathrm{M}-\mathrm{ZSM}-5+\cdot \mathrm{CH}_{3}->\left(\mathrm{CH}_{3}\right)-(\mathrm{HO})-\mathrm{M}-\mathrm{ZSM}-5$

Step 3, formation of methanol

$\left(\mathrm{CH}_{3}\right)-(\mathrm{HO})-\mathrm{M}-\mathrm{ZSM}-5$ ( $\left.\mathrm{CH}_{3} \mathrm{OH}\right)-\mathrm{M}-\mathrm{ZSM}-5$

Step 4, desorption of metanol

$\left(\mathrm{CH}_{3} \mathrm{OH}\right)-\mathrm{M}-\mathrm{ZSM}-5-\mathrm{M}-\mathrm{ZSM}-5+\mathrm{CH}_{3} \mathrm{OH}$

\section{Conclusions}

The results showed that the zeolite catalyst ZSM-5 from fly ash coal and rice husk ash has the potential to be used as catalysts in the partial oxidation of methane to methanol although the catalytic activity of ZSM-5 and Co / ZSM-5 from fly ash coal and rice husk still inferior (7:08\% and methane conversion of $12.43 \%$ ) compared with the catalyst of pro-analysis materials $(28.33 \%$ and $37.65 \%)$ and the commercial catalyst $(9.92 \%$ and $21.36 \%)$. 
This research was funded by : Hibah PUPT BOPTN No. 0545/UN2.R12/HKP/05.00/2015 and BPPT SK No. No.211a/2014

\section{References}

1. Z. Zakaria, S.K. Kamarudin. Renewable and Sustainable Energy Reviews. 65. 250-261 (2016(

2. Bill, A. Wokam, B. Eliasson, E. Killer, U. Kogelschatz, Greenhousegas Chemistry. Energy Conversion and Management, 38 : S415-S422 (1997)

3. Y. Krisnandi, A.P. Putra Bimo, M. Bahtiar, Zahara, M. Abdullah, F. Howe Russell. Procedia Chemistry, 14, 508-515 (2015)

4. Qijian Zhars, Dehua, Qiming Zhu. Journal of Natural Gas Chemistry, 12, 81-89 (2013)

5. Morleza Sohrabi and Leila Vafajoo. World Applied Science Journal, 6, 339-346 (2009)
6. Priyank Khirsariya, Raju K. Mewada. Procedia Engineering, 51, 409-415 (2013)

7. Beznis, Nadzeya V., Bert M. Weckhuysen, Johannes H. Bitter. Catalysis Letters, 136, 52-56 (2010)

8. V. Eugeny, Starokon, V. Mikhail, Perfenov, S. Sergey, I. Arzumanov, Panov. Journal of Catalyst. 300. 47-54 (2013)

9. K. Kordatos, S Gavela, A. Ntiziouni, K.N. Pistiolas, A. Kyritsi, V. Kasselouri-Rigopaulou. Microporous and Mesoporous Material. 189-196 (2008)

10. J. Izidoro J, D.A. Fungaro, F. Santos, S. Wang. Fuel Processing Technology, 97, 38-44 (2012)

11. M.M.J. Treacy and J.B. Higgins. $4^{\text {th }}$ revised ed. Amsterdam, Elsevier, (2001)

12. S. Kulprathipanja. Weinhem, Wiley-VCH Verlag Gmbh and Co. KgaA. (2010)

13. M.F. Fellah, Inal, Isik. J. Phys. Chem, 114, 30423051 (2010) 